\title{
Effect of naloxone and housing conditions on shock-elicited reflexive fighting: Influence of immediate prior stress
}

\author{
ROBERT F. McGIVERN, NANCY J. LOBAUGH, and ALEXIS C. COLLIER \\ Laboratory of Comparative and Physiological Psychology, The Ohio State University \\ Columbus, Ohio 43212
}

\begin{abstract}
The effect of naloxone $(4 \mathrm{mg} / \mathrm{kg})$ on the defensive reaction of shockelicited fighting was studied in male albino rats that were housed individually or in groups for 5 weeks. Naloxone consistently reduced the fighting reflex in both groups, but only when animals were exposed to the reflexive paradigm just prior to the naloxone injection and subsequently retested. Housing conditions also produced an effect on fighting independent of drug manipulation, in that individually housed animals exhibited decreased fighting compared with group-housed animals. Studies of pain sensitivity to shock in group-housed animals injected with naloxone exhibited a pattern similar to that of the fighting response. Naloxone increased pain sensitivity only when the animals were exposed to the shock just prior to drug administration and subsequently retested. Additional group-housed animals were tested with naloxone at lower shock intensities to examine the possibility of a positive linear relationship between pain sensitivity and shock-elicited reflexive fighting. Results did not support a positive relationship between pain sensitivity and fighting, but rather suggested that stress-related endorphin release will facilitate the fighting response. Data are discussed with respect to naloxone's effect on locomotor activity and the association of that activity with adaptive behavior.
\end{abstract}

Recently it has been proposed that endogenous opioids, released under stress, should facilitate speciesspecific defense reactions (SSDRs). This facilitation is proposed to be mediated through the analgesic suppression of protective reflexes (Bolles \& Fanselow, 1980). For the rat, these defense reactions would include freezing, fighting, or fleeing, the elicitation of which would be situation dependent (Bolles, 1970; Bolles \& Collier, 1976). Support for this proposal can be generated from several areas. First, lesion studies have demonstrated the necessity of an intact midbrain central gray for the expression of SSDRs (Edwards \& Adams, 1974; Hunsperger \& Fernandez de Molina, 1962), an area in which the localization and distribution studies of opioid peptides have consistently demonstrated significant quantities of opioids (Atweh \& Kuhar, 1977; Simantov, Kuhar, Uhl, \& Snyder, 1977; Watson, Akil, Richard, \& Barchas, 1978). Second, electrical stimulation of the midbrain central gray produces naloxone-reversible analgesia (Akil, Mayer, \& Liebeskind, 1975). Finally, the re-

Requests for reprints should be sent to the first author, UCLA, Alcohol Research Center, 1010 Westwood Boulevard, Los Angeles, California 90024. Portions of this research were presented at the meeting of the Eastern Psychological Association, New Haven, April 1980. N. J. Lobaugh is now at the University of Texas at Austin. The authors wish to thank Gary G. Berntson and Michael J. Walker for their helpful comments at various stages in the research, and Bradley S. Berson for his generous technical assistance. lease of endogenous opioid peptides in rats, with concurrent analgesia, occurs during acute stress (Akil, Madden, Patrick, \& Barchas, 1976) or in response to a CS signaling the onset of a stressful stimulus (Chance, White, Krynock, \& Rosecrans, 1977).

In the present experiments, we investigated the effect of the opiate antagonist, naloxone, on shockelicited reflexive fighting. This behavior between pairs of rats is characterized by both rats' facing each other in an upright boxing posture, striking with forepaws, and occasionally biting (Ulrich \& Azrin, 1962). The behavior can be reliably produced in response to brief painful footshocks and appears to be stimulus bound (Ulrich \& Azrin, 1962). Recently, this response has been convincingly characterized as a defensive reaction to the painful stimulus wherein pain produces defensive, rather than aggressive, behavior in the rat (Blanchard, Blanchard, \& Takahashi, 1977, 1978).

It has also been noted that isolated rats exhibit less shock-elicited reflexive fighting than do group-housed animals (Ulrich \& Azrin, 1962). Isolation is known to sensitize an animal to the analgesic actions of morphine (Kostowski, Czlonkowski, Rewerski, \& Piechocki, 1977) but to decrease dependence on morphine produced by pellet implantation (Adler, Bendotti, Ghezzi, Samanin, \& Valzelli, 1975). These findings are suggestive of an altered endogenous opioid system. Therefore, we also examined isolated animals with respect to naloxone and shock-elicited reflexive fighting. 


\section{EXPERIMENT 1}

\section{Method}

Subjects. Forty-eight naive male Sprague-Dawley albino rats, obtained from Harlan Labs (Indianapolis) were used as subjects. The animals were approximately 150 days of age at the time of the time of the experiment and weighed between 350 and $450 \mathrm{~g}$. Purina Rat Chow and tap water were available ad lib. Lighting conditions were $12 \mathrm{~h}$ on/off, with the light phase of the cycle beginning at $0600 \mathrm{~h}$.

Apparatus. Shock-elicited reflexive fighting was induced in a 20 $\times 20 \times 28 \mathrm{~cm}$ Plexiglas chamber housed within a well-lighted sound-attenuating cabinet. Shock was delivered by a Lafayette scrambled shocker (Model 82500) programmed to administer a 2-mA, 500-msec shock every $3 \mathrm{sec}$ to the stainless steel grid floor of the test chamber. The grid bars were $.5 \mathrm{~cm}$ wide and spaced $2 \mathrm{~cm}$ center to center.

Procedure. Animals were assigned randomly to either an individual housing condition or a group housing condition ( 2 rats/ cage) for 5 weeks prior to testing. At the end of the 5-week period, individually housed animals were assigned randomly to pairs for testing. These animals were always tested with the same pairmate and subsequently returned to their respective individual cages. Group-housed animals were tested with their cagemates. Each group consisted of 12 pairs of animals.

Testing was done between 1400 and $1800 \mathrm{~h}$. At the beginning of a test session, each pair of animals was allowed $3 \mathrm{~min}$ of habituation in the test chamber before priming. Priming was defined as the first 100 shock presentations administered during the test session. After the habituation period, the animals were presented with the 100 priming shocks, followed by an injection of naloxone $(4 \mathrm{mg} / \mathrm{kg})$ or an equivalent volume of the saline vehicle, and then replaced in the test chamber. Ten minutes postinjection, the animals were presented an additional 100 shocks. Reflexive behavior was scored according to Ulrich and Azrin (1962) by an experimenter in an adjacent room who observed the animals via a closedcircuit video system. Each pair of animals was tested twice, with a 1-week interval imposed between test sessions. Pairs of animals received both saline and naloxone injections in a counterbalanced fashion across the two testing sessions. The test chamber was cleaned with a vinegar/acetic acid/alcohol solution after each pair of rats was tested.

\section{Results and Discussion}

Results revealed that both individual housing and naloxone produced an attenuation of the reflexive fighting response to shock. Data were analyzed by a 2 (housing condition) $\times 2$ (order of drug administration) $\times 4$ (test condition: priming 1 , priming 2 , saline, naloxone) mixed factorial ANOVA (BMD-08V) with repeated measures over the test condition factor. The ANOVA revealed significant main effects for housing $[F(1,20)=15.58, p<.01]$ and test condition $[F(3,20)=7.23, p<.01]$. Post hoc $t$ tests, using the conservative Bonferroni $t$ values to test for differences between test conditions (Myers, 1979), revealed significant differences between the priming 1 and naloxone $[\mathrm{t}(60)=3.89, \mathrm{p}<.01]$, the priming 2 and naloxone $[\mathrm{t}(60)=3.52, \mathrm{p}<.05]$, and the saline and naloxone $[\mathrm{t}(60)=2.90, \mathrm{p}<.05]$ conditions. No differences were detected between the priming and saline comparisons. Data are presented in Figure 1.

These data indicate that naloxone will attenuate shock-elicited reflexive fighting if the animals have

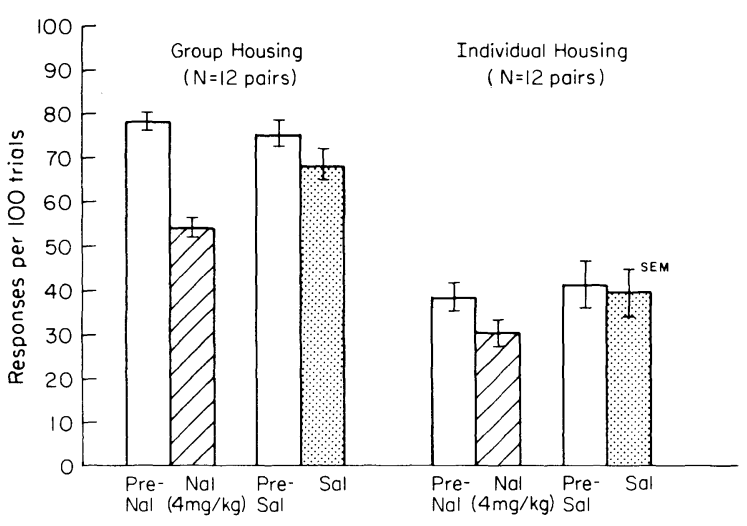

Figure 1. The mean number of fighting responses at $2 \mathrm{~mA}$ after naloxone and saline when animals were exposed to priming trials.

experienced the shock just prior to drug administration. Naloxone was effective in reducing the number of responses in individually housed animals as well as in group-housed animals, even though the individually housed animals exhibited only half the number of responses of the group-housed animals during the priming and saline trials.

\section{EXPERIMENT 2}

This experiment was designed to test whether naloxone would attenuate shock-elicited reflexive fighting if administration of the drug preceded shock experience. This procedure would functionally prevent the endogenous opioid system from being activated by the stress through the occupation of the opioid receptor site by naloxone.

\section{Method}

Subjects and Apparatus. Twenty-four adult naive male SpragueDawley albino rats, obtained from Harlan Labs, approximately 150 days of age, and weighing between 350 and $450 \mathrm{~g}$, were used as subjects. Housing and maintenance conditions paralleled those in Experiment 1. The test apparatus was the same as that used in Experiment 1.

Procedure. The same testing procedures used in Experiment 1 were followed, with the exception that the animals received no priming experience before administration of the drug. Each pair of animals was injected with saline or naloxone $(4 \mathrm{mg} / \mathrm{kg}) 10 \mathrm{~min}$ prior to testing in two separate test sessions. Testing sessions were spaced 1 week apart, and pairs of animals received both drugs in a counterbalanced design over the two test sessions.

\section{Results and Discussion}

The results revealed an effect for housing conditions similar to that observed in Experiment $1[\mathrm{~F}(1,20)$ $=8.74, \mathrm{p}<.01]$, but, under the present conditions, naloxone was without effect. Data were analyzed by a 2 (housing condition) $\times 2$ (order) $\times 2$ (test session: saline or naloxone) ANOVA (BMD-08V) with repeated measures over the last factor. No other significant main effects or interactions were revealed, 


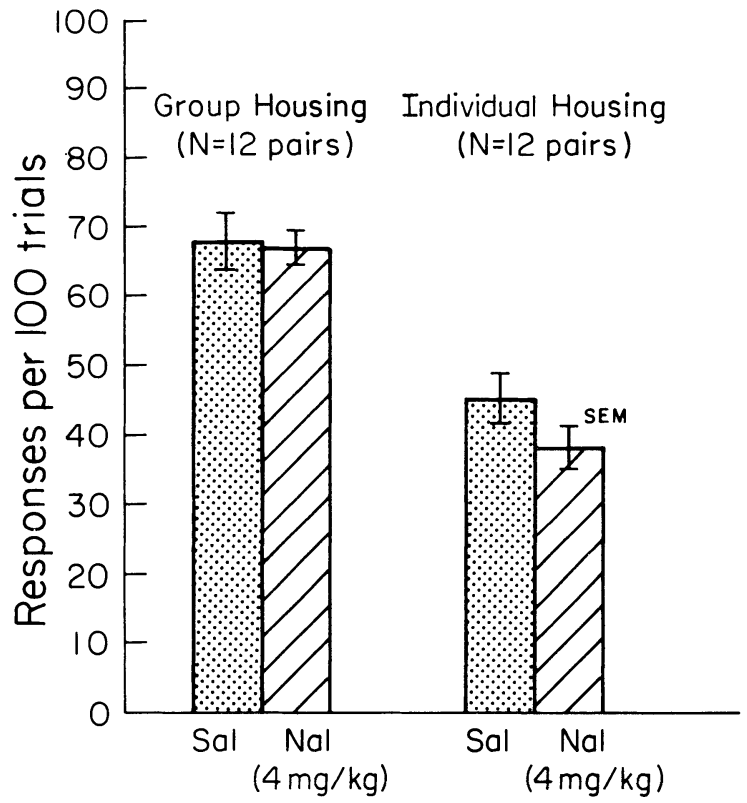

Figure 2. The mean number of fighting responses at $2 \mathrm{~mA}$ after naloxone and saline when animals received no priming trials.

indicating that naloxone was ineffective in reducing shock-elicited reflexive fighting. Data are presented in Figure 2.

These results replicate the effects of housing conditions observed in Experiment 1, but indicate that naloxone is ineffective if a stress-related opioid system has not been functionally activated prior to naloxone administration.

\section{EXPERIMENT 3}

To test whether the effects of naloxone were specific to shock-elicited reflexive fighting or simply reflected an increase in pain sensitivity, three groups of animals were tested in the shock jump test. In Experiment 3, two groups of animals were given priming exposure to the shock before naloxone or saline injections. In Experiment 4, animals were administered naloxone or saline in a counterbalanced order with no priming exposure to the shock.

\section{Method}

Subjects. Twelve naive male Sprague-Dawley albino rats, obtained from Simonson Labs (Gilroy, California), were used as subjects. The animals were approximatley 120 days of age and weighed between 375 and $425 \mathrm{~g}$ at the time of the experiment. Housing and maintenance conditions paralleled those reported in Experiment 1.

Apparatus. The testing apparatus consisted of a bronze grid placed on a $15 \times 26.5 \times .2 \mathrm{~cm}$ metal platform that was placed over a $15 \times 26.5 \times 2.5 \mathrm{~cm}$ piece of foam rubber. A transducer, fixed directly under the center of the foam, transmitted the magnitude of the rat's jump response to a shock stimulus to a Grass polygraph (Model 7B), where the response was recorded in millimeters of pen deflection. The transducer consisted of an LED and photocell fixed in epoxy. The amount of light striking the photocell was proportional to the amount of compression of the foam pad. ${ }^{1}$ During testing, the animal was confined within a $14-\mathrm{cm}$ diam $\times 19-\mathrm{cm}$-high glass cylinder centered over the transducer. The restraining cylinder restricted the animal's lateral movement on the grid. Shock was delivered to the grid by a BRS scrambled shocker that was programmed to deliver a 2-mA, 500-msec shock every $10 \mathrm{sec}$.

Procedure. An animal was placed in the apparatus and given three initial shocks to adjust the sensitivity of the dc preamplifier to reflect a 30-40-mm pen deflection to the jump response. Since maximum pen deflection was approximately $65 \mathrm{~mm}$ from baseline, this procedure allowed the maximum latitude for the pen deflection to reflect a change in the animal's response to the shock. The initial baseline preamplifier sensitivity established for each animal was used throughout the remainder of the experiment for that animal. The animals were assigned randomly to two groups, one that received saline and one that received naloxone $(\mathrm{N}=6$ / group).

The formal testing procedure immediately followed the establishment of baseline sensitivity and consisted of presenting a shock every $10 \mathrm{sec}$ for $3 \mathrm{~min}$, resulting in a total of 18 shocks. Subsequently, the animal was weighed and administered an injection (ip) of naloxone $(4 \mathrm{mg} / \mathrm{kg}$ ) or an equivalent volume of saline. Ten minutes postinjection, the animal was retested with an additional 3 min of the shock schedule. The apparatus was cleaned, as in Experiment 1, before each animal was tested.

\section{Results}

The results indicated that naloxone produced an increase in pain sensitivity when administered shortly after an initial shock experience. Data were analyzed by paired $t$ test comparing the mean of the predrug trials with the mean of the postdrug trials. The group that received naloxone exhibited a significant increase in the jump response [t $(5)=2.23, \mathrm{p}<.05$ ], whereas no significant change was observed in the saline-treated group. Data are presented in Table 1.

\section{EXPERIMENT 4}

\section{Method}

Subjects. The subjects were six naive Sprague-Dawley albino rats obtained from Simonson Labs (Gilroy, California). The animals were approximately 120 days of age and weighed between 350 and $425 \mathrm{~g}$ at the time of the experiment. Housing and main-

Table 1

Mean Pen Deflection (in Millimeters) on the Shock-Jump Test for Rats Receiving Saline or Naloxone Drug Treatments

\begin{tabular}{|c|c|c|c|c|c|}
\hline & & \multicolumn{2}{|c|}{ Saline } & \multicolumn{2}{|c|}{ Naloxone } \\
\hline & & Mean & SEM & Mean & SEM \\
\hline \multirow{3}{*}{ Priming } & \multirow{3}{*}{$\begin{array}{l}\text { Predrug } \\
\text { Postdrug }\end{array}$} & \multicolumn{4}{|c|}{$\begin{array}{c}\text { Experiment } 3 \\
\text { (Between-Subjects Design, } \\
\mathrm{n}=6 \text { per Drug Condition) }\end{array}$} \\
\hline & & $\begin{array}{l}38.39 \\
35.71\end{array}$ & $\begin{array}{l}3.08 \\
5.34\end{array}$ & $\begin{array}{l}30.80 \\
40.24\end{array}$ & $\begin{array}{l}4.80 \\
5.61\end{array}$ \\
\hline & & \multicolumn{4}{|c|}{$\begin{array}{c}\text { Experiment } 4 \\
\text { (Within-Subjects Design, } \\
\text { Total } n=6 \text { ) }\end{array}$} \\
\hline No Priming & & 33.59 & 3.22 & 36.87 & 3.87 \\
\hline
\end{tabular}

Note-Data for Experiment 4 are presented with drug order collapsed. 
tenance conditions were the same as those for the group-housed animals in Experiment 1.

Apparatus. The apparatus was the same as that used in Experiment 3.

Procedure. A within-subject design was employed, with each animal being tested with both naloxone and saline in two separate test sessions. Order of drug administration was counterbalanced, and testing sessions were spaced $48 \mathrm{~h}$ apart.

Before the animal's first testing session, it was weighed and injected in the experimental room 10 min prior to shock administration. To avoid possible "autoanalgesia" (Chance et al., 1977) during the second testing session, the animals were injected in their home cages in the vivarium before the second test, $10 \mathrm{~min}$ prior to shock presentation.

\section{Results and Discussion}

The results of this experiment revealed no significant effects of naloxone or saline on the shock-jump response (see Table 1). Data were analyzed as in Experiment 2. Thus, as in Experiment 2, naloxone produced no detectable effects when administered prior to the stressful shock experience. However, in Experiment 3, when the drug was administered just after the stressful experience prior to a subsequent retest, pain sensitivity appeared to increase. These results suggested that the decrease observed in reflexive behavior in Experiment 1 was due to increased pain sensitivity produced by naloxone. We tested this hypothesis more directly in Experiment 5.

\section{EXPERIMENT 5}

Ulrich and Azrin (1962) reported an inverted Ushaped shock-intensity function for shock-elicited reflexive fighting which we have recently confirmed in our laboratory (Lobaugh, Note 1). According to this function, $2 \mathrm{~mA}$ produces the maximum number of responses, with higher or lower shock intensities both producing a reduction in the number of responses. Therefore, if a positive linear relationship existed between pain perception and reflexive fighting, it would result in decreased fighting because the perceived intensity function would be shifted to the right. We tested this relationship by testing animals at lower shock intensities to circumvent the ceiling effects in responses produced by the $2-\mathrm{mA}$ intensity. The animals were primed as described in Experiment 1, but shock intensities were lowered to .75 or $1.3 \mathrm{~mA}$.

\section{Method}

Subjects. Twenty-four naive Sprague-Dawley male albino rats obtained from Harlan Labs were used as subjects. The animals were between 130 and 150 days of age at the time of testing and weighed between 350 and $450 \mathrm{~g}$. All animals were group housed with their testing mates, as described in Experiment 1.

Apparatus and Procedures. The apparatus and the procedures were identical to those described in Experiment 1 . Six pairs of animals were tested at the $.75-\mathrm{mA}$ intensity and six pairs were tested at the 1.3-mA intensity.

\section{Results and Discussion}

The results obtained from the experiment using the .75-mA intensity were inconclusive since only three

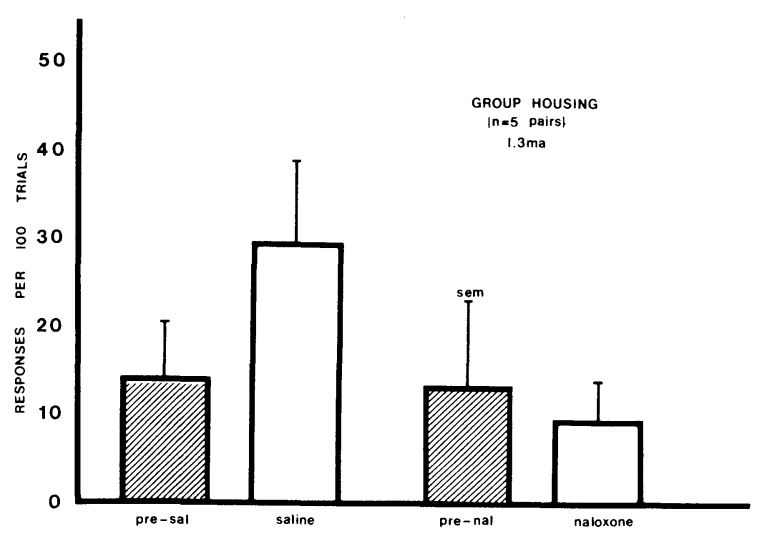

Figure 3. The mean number of fighting responses at $1.3 \mathrm{~mA}$ after naloxone and saline when animals were exposed to priming trials.

pairs of animals exhibited fighting under the priming/ naloxone condition and only one pair exhibited fighting under the priming saline condition. This lack of fighting precluded any statistical analysis. However, the number of fighting responses observed after naloxone for the three pairs that did respond was always lower than the number of fighting responses observed during the preceding priming condition (priming, mean $=37.33$; naloxone, mean $=23.67$ ). None of the animals that failed to exhibit fighting responses during the priming trials exhibited the behavior after a subsequent naloxone injection.

The data obtained from the 1.3-mA intensity were more revealing. Five of the six pairs exhibited fighting under all of the testing conditions. The pair that did not exhibit consistent fighting was dropped from the analyses. Data were analyzed by paired $t$ tests comparing the priming trials with the subsequent naloxone or saline trials. No differences were observed in the priming trials between the two testing sessions, as can be seen in Figure 3. The response to naloxone at this intensity was similar to that observed at the 2 - and .75-mA intensities in that the drug produced a decrease in fighting rather than the expected increase. The results, however, were not significant [priming, mean $=13.4$ (S.E.M. $=9.5$ ); naloxone, mean $=9.4$ (S.E.M. $=4.52$ ); $\mathrm{t}(4)=.63$, n.s.). The lower intensity did reveal a significant increase in fighting between the priming and saline condition for the same animals [priming, mean $=14.2$ (S.E.M. =6.65); saline, mean $=29.4$ (S.E.M. $=9.75$ ); $\mathrm{t}(4)=$ $2.51, \mathrm{p}<.05$ ]. This effect of priming can be seen in Figure 3.

\section{GENERAL DISCUSSION}

The results from these studies reveal a complex pattern for the role of naloxone-sensitive opioids in shock-elicited reflexive fighting. The findings of Experiment 1 demonstrated that naloxone will signifi- 
cantly attenuate this behavior if administered just after the animals have experienced exposure to the paradigm and are then subsequently retested. The results from Experiment 2 suggest that this "priming" shock is necessary for naloxone to produce a detectable change in the response. The "priming" phenomenon also has previously been observed by Fanselow and Bolles (1979) with respect to the effects of naloxone on freezing behavior.

The shock-jump experiments were designed to test whether this naloxone-induced attenuation in reflexive behavior might reflect increased pain sensitivity. Goldstein (1976) originally proposed that there was an opioid system that was not tonically active, but responded acutely to stress, thereby raising pain thresholds. This proposal has been confirmed by others (Akil et al., 1976; Rossier, French, Rivier, Ling, Guillemin, \& Bloom, 1977) and extended to demonstrate that naloxone will conversely lower pain thresholds in an opiate naive animal (Berntson \& Walker, 1977; Jacob, Tremblay, \& Columbel, 1974). Further studies (Chance et al., 1977; Kaplan \& Glick, 1979) indicate that this naloxone-induced hyperalgesia is due to the actions of this opiate antagonist in counteracting conditioned opioid release. Thus, naloxone-induced hyperalgesia appears to be produced through the acute inactivation of an opioid system by the opiate blocker after opioid release rather than preventing the system from being activated by receptor occupation before opioid release. This hypothesis would explain why naloxone was effective in increasing the jump response subsequent to prior shock experience (Experiment 3), but ineffective when the animal had no immediate prior experience and was injected in the home cage before the second test (Experiment 4).

Bolles and Fanselow (1980) have proposed that opioid release will facilitate species-specific defense reactions by causing an analgesic suppression of protective reflexes. Data from Experiment 5 support this proposal in that defensive fighting was increased in animals receiving saline. Further support is derived from the findings of Experiment 1, which demonstrated that animals decreased their fighting during the second set of trials when administered naloxone. However, this hypothesis is challenged by the finding of Fanselow and Bolles (1979), which showed that naloxone produced an increase rather than a decrease in freezing behavior in the rat if the rat had received at least one prior shock. This inconsistency may reflect the more general effects of naloxone on locomotor activity. A number of reports have consistently observed a depressive action of this drug on locomotor activity of rats (Amir, Solomon, \& Amit, 1979; Arnsten \& Segal, 1979; Rogers \& Deacon, 1979; Walker, Berntson, Paulucci, \& Champney, 1981). In contrast, central administration of low doses of endogenous opioids and morphine increase locomotor activity (Pert, DeWald, Liao, \& Sivit, 1979). Consistent with these findings, it might be predicted that the administration of naloxone would result in freezing behavior as well as the decrease in reflexive fighting observed in the present study.

The data from the first four experiments suggested that naloxone affected shock-elicited reflexive fighting at $2 \mathrm{~mA}$ by increasing the painfulness of the shock. According to the U-shaped function of the relationship between fighting responses and shock intensities described by Ulrich and Azrin (1962), $2 \mathrm{~mA}$ is the optimal shock intensity to produce maximal fighting. Therefore, we hypothesized that naloxone-induced hyperalgesia produced a functional increase in the perceived painfulness of the shock, thereby decreasing the number of observed fighting responses. However, the data from Experiment 5 did not confirm the hypothesis that there was an underlying positive linear relationship between pain sensitivity and the effect of naloxone on reflexive fighting. Additionally, data obtained from the priming/saline condition at $1.3 \mathrm{~mA}$ suggests that stressrelated opioid release will facilitate this behavior.

One possible explanation of these effects may be that endogenous opioids, acting at brainstem sites to inhibit nociceptive stimuli (see North, 1979, for review), may serve to facilitate locomotor activity associated with a broad range of adaptive behaviors whose integration appear to be intrinsic to brainstem networks (Berntson \& Micco, 1976; Siegel, 1979). This would include the facilitation of such behaviors as defensive fighting, grooming, eating, and drinking, all of which have been convincingly argued to be dependent upon brainstem neuronal networks (Berntson \& Micco, 1976). Moreover, all of these behaviors are attenuated by naloxone (Gispen, Weigant, Bradbury, Hulme, Smyth, Snell, \& DeWied, 1976; Holtzman, 1975, 1979; Rogers \& Deacon, 1979). In contrast, lesions of the midbrain central gray have been shown to abolish shock-elicited aggression and freezing (Edwards \& Adams, 1974) and spontaneous activity (Bailey \& Davis, 1942; Skultety, Meyers, \& Brown, 1954), as well as to impair responses to noxious stimuli (Halpern, 1968; Skultety, 1958). As noted in the introduction, this integrative brainstem area exhibits a relatively dense population of opiate receptors.

Finally, the results of the present study confirm the earlier observation by Ulrich and Azrin (1962) that isolation will reduce shock-elicited reflexive fighting, a phenomenon also confirmed in another recent study (Knutson \& Kane, 1980). Nishikawa and Tanaka (1981) have shown that isolation will attenuate the rat's response to electric shock and that this effect appears to be mediated in part by isolation-induced supersensitivity of central catecholaminergic neurons. In the present experiments, isolated animals exhibit a decrease in fighting after naloxone compared with baseline levels, similar to the decrease observed with 
group-housed animals. Although it is known that isolated animals exhibit altered responsivity to morphine (Adler et al., 1975; Kostowski et al., 1977), it remains to be demonstrated that isolation of the adult rat produces chronic changes in an endogenous opioid system.

\section{REFERENCE NOTE}

1. Lobaugh, N. J. Unpublished observations, July 1979.

\section{REFERENCES}

Adle R, M. W., Bendotti, D., Ghezzi, D., Samanin, R., \& VAlzelli, L. Dependence to morphine in differentially housed rats. Psychopharmacologia (Berlin), 1975, 41, 15-18.

Akil, H., Madden, J., Patrick, R. L., \& Barchas, J. D. Stress-induced increase in endogenous opiate peptides: Concurrent analgesia and its partial reversal by naloxone. In Opiates and endogenous opioid peptides. Amsterdam: Elsevier/NorthHolland, 1976.

Akil, H., Mayer, D. J., \& Liebeskind, J. C. Antagonism of stimulation-produced analgesia by naloxone, a narcotic antagonist. Science, 1975, 191, 961-962.

Amir, S., Solomon, M., \& Amit, Z. The effect of acute and chronic naloxone administration on motor activation in the rat. Neuropharmacology, 1979, 18, 171-173.

Arnsten, A. T., \& Segal, D. S. Naloxone alters locomotion and interaction with environmental stimuli. Life Sciences, 1979, 25, 1035-1042.

ATWeh, S. F., \& KuhaR, M. J. Autoradiographic localization of opiate receptors in rat brain. II. The brain stem. Brain $R e$ search, 1977, 129, 1-12.

Bailey, P., \& DAvis, E. Effects on lesions of the periacqueductal gray matter in the cat. Proceedings of the Society for Experimental Biological Medicine, 1942, 51, 305-306.

Berntson, G. G., \& Micco, D. J. Theoretical review: Organization of brainstem behavioral systems. Brain Research Bulletin, 1976, 1, 471-483.

Berntson, G. G., \& Walker, J. M. Effect of opiate receptor blockade on pain sensitivity in the rat. Brain Research Bulletin, 1977, 2, 157-159.

Blanchard, R. J., Blanchard, D. C., \& Takahashi, L. K. Reflexive fighting in the albino rat: Aggressive or defensive behavior? Aggressive Behavior, 1977, 3, 145-155.

Blanchard, R. J., Blanchard, D. C., \& Takahashi, L. K. Pain and aggression in the rat. Behavioral Biology, 1978, 23, 291-305.

Bolles, R. C. Species-specific defense reactions and avoidance learning. Psychological Review, 1970, 77, 32-48.

Bolles, R. C., \& Collier, A. C. The effect of predictive cues in freezing in rats. Animal Learning \& Behavior, 1976, 4, 6-8.

Bolles, R. C., \& Fanselow, M. S. A perceptual-defensiverecuperative model of fear and pain. Behavioral and Brain Sciences, 1980, 3, 291-323.

Chance, W. T., White, A. C., Krynock, G. M., \& Rosecrans, J. A. Autoanalgesia: Behaviorally activated autinociception. European Journal of Pharmacology, 1977, 44, 283-284.

Edwards, M. A., \& Adams, D. B. Role of midbrain central gray in pain-induced defensive boxing of rats. Physiology \& Behavior, 1974, 13, 113-121.

Fanselow, M. S., \& Bolles, R. C. Naloxone and shock elicited freezing in the rat. Journal of Comparative and Physiological Psychology, 1979, 93, 736-744.

Gispen, W. H., Weigant, V. M., Bradbury, A. F., Hulme, G. C., Sмyth, D. C., SNell, C. R., \& DeWeid, D. Induction of excessive grooming in the rat by fragments of lipotropin. Nature, 1976, 264, 794-795.

Goldste in, A. Opioid peptides in pituitary and brain. Science, 1976, 193, 1081-1086.

HALPERN, M. Effects of midbrain central gray matter lesions on escape avoidance behavior in rats. Physiology \& Behavior, 1968, 3, 171-178.

Holtzman, S. G. Effects of narcotic antagonists on fluid intake in the rat. Life Science, 1975, 16, 1465-1470.

Holtzman, S. G. Suppression of appetitive behavior in the rat by naloxone: Lack of effect of prior morphine dependence. Life Science, 1979, 24, 219-226.

Hunsperger, R. W., \& Fernandez de Molina, A. Organization of the subcortical system governing defense and flight reactions in the cat. Journal of Physiology (London), 1962, 160, 200-213.

Jacob, J. J., Tremblay, E. L., \& Columbel, M. C. Facilitation de réactions nocioceptives par le naloxone chez la souris et chez le rat. Psychopharmacologia, 1974, 37, 217-223.

KaPlan, R., \& Glick, S. D. Prior exposure to footshock induced naloxone hyperalgesia. Life Sciences, 1979, 24, 2309-2312.

KNUTSON, J. F., \& KANE. N. The effects of social isolation on two shock-induced aggressive responses in rats. Animal Learning \& Behavior, 1980, 8, 167-170.

Kostowski, W., Czlonkowski, A., Rewerski, W., \& Piechocki, T. Morphine action in group and isolated rats and mice. Psychopharmacology, 1977, 53, 191-193.

MYERS, J. L. Fundamentals of experimental design (3rd ed.). Boston: Allyn \& Bacon, 1979.

NishikawA, T., \& TANAKa, M. Altered behavioral responses to intense footshock in socially isolated rats. Pharmacology, Biochemsitry and Behavior, 1981, 8, 61-67.

North, R. A. Opiates, opioid peptides and single neurons. Life Science, 1979, 24, 1527-1546.

Pert, A., DeWald, L. A.; Liao, H., \& Sivit, C. Effects of opiates and opioid peptides on motor behaviors: Sites and mechanisms of action. In E. Usdin, W. E. Bunney, \& N. Kline (Eds.), Endorphins in mental health research. London: Macmillan, 1979.

Rogers, R. J., \& Deacon, R. M. J. Effect of naloxone on the behavior of rats exposed to a novel environment. Psychopharmacology, 1979, 65, 103-105.

Rossier, J., French, E. D., Rivier, C., Ling, N., Guillemin, R., \& BLOoM, F. E. Footshock induced stress increases $\beta$ endorphin levels in blood but not brain. Nature, 1977, 220, 618-620.

SiEgeL, J. M. Behavioral functions of the reticular formation. Brain Research Reviews, 1979, 1, 69-105.

Simantov, R., Kuhar, M. J., Uhl, G. R., \& Snyder, S. H. Opioid peptide enkephalin: Immunohistochemical mapping in rat central nervous system. Proceedings of the National Academy of Sciences (U.S.A.), 1977, 74, 2167-2171.

Skultety, F. M. The behavioral effects of destructive lesions of the periacqueductal gray matter in adult cats. Journal of Comparative Neurology, 1958, 110, 337-366.

Skultety, F. M., Meyers, R., \& Brown, G. Behavioral effects of electrolytic lesions of the periacqueductal gray matter in cats. Transactions of the American Neurological Association, 1954, 79, 121-126.

Ulrich, R. E., \& Azrin, N. H. Reflexive fighting in response to aversive stimulation. Journal of the Experimental Analysis of Behavior, 1962, 5, 511-520.

Walker, J. M., Berntson, G. G., Paulucci, T.S., \& Champney, T. C. Blockade of endogenous opiates reduces activity in the rat. Pharmacology, Biochemsitry and Behavior, 1981, 14, 113116.

Watson, S. J., Akil, H., Richard, C. W., \& Barchas, J. D. Evidence for two separate opiate peptide neuronal systems. Nature, 1978, 275, 226-228.

\section{NOTE}

1. This device was designed and engineered by Robert Isenhart, Fairview Hospital, Costa Mesa, California.

(Manuscript received September 30, 1980; revision accepted for publication July 23,1981 .) 